\title{
Exposure to Cyberbullying, Cybervictimization, and Related Factors Among Junior High School Students
}

\author{
Maryam Mohseny ${ }^{1}$, Zahra Zamani (iD ${ }^{2,}{ }^{,}$, Shahin Akhondzadeh Basti ${ }^{3}$, Mohammad-Reza Sohrabi (iD) ${ }^{1}$, \\ Ali Najafi iD ${ }^{4}$ and Farzad Tajdini ${ }^{1}$ \\ ${ }^{1}$ Community Medicine, Shahid Beheshti University of Medical Sciences, Tehran, Iran \\ ${ }^{2}$ Community Medicine, Tehran University of Medical Sciences, Tehran, Iran \\ ${ }^{3}$ School of Medicine, Tehran University of Medical Sciences, Tehran, Iran \\ ${ }^{4}$ Medical Library and Information Sciences, Tehran University of Medical Sciences, Tehran, Iran \\ "Corresponding author: Community Medicine, Tehran University of Medical Sciences, School of Medicine, Poursina ST, PO. Box: 14155-6447, Tehran, Iran. Tel: +98-9125804350. \\ Email: zamanizhm@gmail.com
}

Received 2019 November 16; Revised 2020 April 12; Accepted 2020 November 21.

\begin{abstract}
Background: While social media have an immense effect on children and adolescent interactions, they also have serious and potential effects on physical and mental health. Cyberbullying, as a form of bullying using electronic means, is an example of this trend.

Objectives: The purpose of this study was to determine the prevalence of cyber-related behaviors and some of their related factors among high school students in Tehran.

Methods: This was a cross-sectional analytical study examining cyber behaviors in students in grades 7, 8, and 9 . Since our study was conducted in line with an international study, we used the questionnaire of that research to collect data. Some of the characteristics of the adolescents and behavioral problems associated with them were examined, and students' experiences of cyberbullying and cybervictimization were asked in this study. A multi-stage cluster sampling was performed. The statistical population consisted of students from five districts of north, south, west, east, and center regions of Tehran, in which 1,456 questionnaires were completed. Results: The prevalence rate of cyberbullying was $22.3 \%$ while that of cybervictimization was $18 \%$. It was also demonstrated that both trends were more significant in boys than in girls. Other parameters such as substance use, body thought scale, school environment difficulties, peer, conduct, and emotional problems had significant correlations with cybervictimization ( $\mathrm{P}=0.03$ for peer problems to $\mathrm{P}<0.001$ for emotional problems) and cyberbullying $(\mathrm{P}<0.04$ for peer problems to $\mathrm{P}<0.001$ for school environment). A significant relationship was also found between prosocial problems and cyberbullying $(\mathrm{P}=0.01)$.

Conclusions: Cyberbullying and cybervictimization are more prevalent in boys than in girls. This phenomenon is related to many physical and mental health problems. This evidence can be used to inform decision-makers in the social arena to provide strategies for preventive programs and future interventions.
\end{abstract}

Keywords: Adolescent, Cyberbullying, Cybervictimization, Prevalence, School Health

\section{Background}

Bullying in school is an important problem everywhere in the world, and many students are likely to experience this phenomenon in their relationships with their classmates (1). Communication technologies such as social media, mobile phones, and the internet are used at increasing rates that have provided convenience; but they can also potentially expose the users to dangerous relationships that may endanger their physical and mental health. In a recent study, about one-third of adolescents reported being involved in cyberbullying as either a perpetrator, a victim, or both (2). Many previous studies noted a gender difference in the cyberbullying prevalence. For instance, in a systematic review conducted in Spain, a higher rate of cyberbullying behavior was shown among boys with a prevalence up to $72 \%$ (3), and a meta-analysis of 109 studies conducted in 2014 showed that boys were more likely than girls to cyber-bully during early to mid-adolescence (4). Some of the known risk factors for cyberbullying include living with non-biological parents, perceptual problems, not feeling safe at school, hyperactivity, and emotional, peer, and conduct problems. However, some studies have shown that cybervictim suffer from emotional problems and peer problems more than cyberbullying perpetrators (5). 
Cybervictimization has been associated with internalizing difficulties such as depression, loneliness, isolation, peer rejection, feeling of hopelessness, lower life satisfaction, suicidal ideation, suicide attempts, smoking and substance use, and anxiety symptoms (6). Students with disabilities are at an increased risk of experiencing cyberbullying than their peers without disabilities (7). Smoking and alcohol drinking are frequently seen in teenage bullies and victims, and also illicit drug use and sexually risky behaviors are reported in victimized male and female adolescents (8). The victims of cyberbullying often suffer from low self-esteem, insecurity, poor grades in school, and the inability to feel safe at their homes. One of the most important side effects in students who are cyberbullied is personality changes that make them withdrawn and moody rather than outgoing and social; thus, they do not tend to go to school and become distracted after being online or checking text messages (9). Suicide is another devastating outcome of cyberbullying victimization, which can increase suicidal thoughts by $14.5 \%$ and suicide attempts by $8.7 \%$, and these effects are greater in men than in women (10). Besides, cyberbullying has psychosomatic symptoms (headaches, stomachache, etc.) and a lack of feeling safe in school (11). Cyberbullying students commit crimes and carry weapons inside and outside the school more than others (5).

The increasing use of social media among adolescents has caused the exacerbation of cyberbullying as a serious public health problem. These effects have been considered in previous traditional bullying investigations (12). Although studies have been conducted on the prevalence and consequences of cyberbullying in Iran, more studies are needed due to the importance of the subject (13).

\section{Objectives}

This research was the first study on cyberbullying in Iran that was conducted in the framework of an international comparative study representing Finland, which was simultaneously conducted in several European and Asian countries. The main purpose of our study was to evaluate the prevalence of cyber behaviors. Another important purpose was to evaluate the relationship between cyberbullying and cybervictimization in high school students and related factors mentioned in a questionnaire given to high school students.

\section{Methods}

\subsection{Participants and Sampling}

This was a cross-sectional analytical study. We used a multi-stage cluster sampling method to select among male and female students from governmental and nongovernmental schools. The Equation 1 was implemented to calculate the sample size. About one-third of adolescents, based on previous studies, reported being involved in cyberbullying as either a perpetrator, a victim, or both (2). Therefore according to the formula $\alpha=0.05, z_{1-\frac{\alpha}{2}}^{2}=(1.96)^{2}$ $=3.84, \mathrm{p}=0.35, \mathrm{~d}=0.025$; the sample size was calculated about 1400 students.

$n=\frac{z_{1-\frac{\alpha}{2}}^{2} \times p q}{d^{2}}$

\subsection{Study Design}

The study was approved by the Ethics Committee of Tehran University of Medical Sciences (1394.1413). The printed questionnaires were anonymous and distributed by four experienced interviewers (two men for boys and two women for girls). First, participants' informed consent was received. Participants were informed of the confidentiality of their responses and that the responses would be used only for research purposes. The students completed the questionnaires, and each questionnaire took an average of about 20 min to be completed. Over a period of six months, a total of 20 schools were studied in the five areas.

\subsection{Study Protocols and Instruments}

The research was part of an international comparative study on behalf of the Finland study, which was also conducted in several European and Asian countries. We used a comprehensive questionnaire designed for all countries that participated in this study. This questionnaire was first used in 2004 by André Sourander, the original designer of the project (14). We prepared the questionnaire based on a back-translation and used the Persian printed version. Cronbach's alpha was used for the reliability of the translated questionnaire, which was 0.73 for internal consistency (reliability). The validity and internal consistency of the Strengths and Difficulties Questionnaire (SDQ) were evaluated by Tehrani-Doost et al. in 2009, and strong correlations were found among subscales (15). The questionnaire included sections such as demographics, background, family status, aches and sleep, personal health, substance use and smoking, thoughts about their body, SDQ, experience about the need for outside help, struggles, suicidality, school environment, and experiences of cyberbullying. About 1,456 questionnaires were used to collect data. The gathered data included basic information on cyber behavior, feeling safe at school, psychosomatic symptoms (headache, stomachache, sleep problems), trying to get help from others, and high-risk behaviors.

The main part of the questionnaire was the SDQ subsection, which is an instrument for screening behavioral 
and emotional problems in children and adolescents (16). The SDQ was developed by Goodman for mental and behavioral problem screening in children and adolescents (17). This questionnaire was used in previous studies in Finland (18). The reliability and validity of the SDQ were calculated by Goodman et al. (19). The SDQ is a behavioral screening tool consisting of 25 items. For each item in this structure, a score is determined from 1 to 3 ( 1 =Not true, $2=$ Somewhat true, 3 = completely true). The 25 SDQ items are divided between 5 scales of 5 items each, according to the instructions, included hyperactivity scale, conduct problems scale, emotional symptoms scale, peer problems scale, and prosocial scale (20). Variables such as thoughts about their body, school environment, smoking, and substance use were computed concerning cyberbullying and cybervictimization (Table 1 ). After collecting the questionnaires, we calculated the prevalence of cyberbullying and cybervictimization and their relationships with the variables mentioned.

\subsection{Statistical Analyses}

To perform statistical analysis, SPSS 22 software was used. We also conducted descriptive and analytic statistics to determine data distribution and the association between different variables and cyberbullying behaviors. To determine the association of demographic and qualitative variables with cyberbullying and cybervictimization, the Chi-square test was used. The t-test, Mann-Whitney test, and ANOVA test were used to assess the relationship between cyberbullying behaviors and quantitative variables. We used linear regression analysis as a model to predict cyberbullying behaviors.

\section{Results}

\subsection{Descriptive Findings}

In this study, 1,456 questionnaires were completed by the students (794 boys and 662 girls). Overall, these results indicated that the prevalence of cyberbullying was $22.3 \%$ and that of cybervictimization was $18 \%$. Also, cyberbullying in boys (26.4\%) was significantly greater than in girls (17.3\%). Likewise, cybervictimization was significantly present at a higher rate in boys (19.5\%) than in girls (16.1\%). Table 2 illustrates the demographic characteristics of the participants.

\subsection{Analytical Findings}

The relationship between the demographic characteristics of participants with cyberbullying and cybervictimization is shown in Table 3. The age group, gender, and school grade had significant correlations with cyberbullying and cybervictimization. Cybervictimization was more prevalent at ages of $16-17$ years $(21.9 \%, \mathrm{P}=0.002)$, in boys $(19.5 \%, \mathrm{P}=0.05)$, and in the ninth grade $(21.2 \%, \mathrm{P}<0.001)$. Additionally, cyberbullying was higher in the 16 - 17 age group (24\%, $\mathrm{P}=0.002)$, in boys $(26.4 \%, \mathrm{P}<0.001)$, in the eighth grade $(26.4 \%, \mathrm{P}<0.001)$, and in private high schools (30.2\%, $\mathrm{P}=0.008)$.

Table 3 shows significant correlations between noncyber and cybervictimization and weight (58.12 vs. 61.95; P $=0.001$ ), height (165.23 vs. 167.3; $\mathrm{P}<0.001)$, peer problems (1.76 vs. $1.8 ; \mathrm{P}=0.03)$, conduct problems (1.49 vs. $1.65 ; \mathrm{P}<$ 0.001), emotional problems (1.42 vs. $1.57 ; \mathrm{P}<0.001$ ), body attitude problem (2.21 vs. $2.14 ; \mathrm{P}=0.001)$, problems related to school environment ( 2.52 vs. $2.34 ; \mathrm{P}<0.001)$ and personal smoking and substance use (1.86 vs. $1.76 ; \mathrm{P}=0.02)$.

Also, age, height, peer problems, conduct problems, prosocial problems, emotional problems, body attitude problems, problems related to the school environment, and smoking and substance use indicated significant correlations with cyberbullying. The mean variables in both subtypes included height 165.24 vs. 168.11 ( $\mathrm{P}<0.001)$, peer problems 1.76 vs. 1.8 ( $\mathrm{P}<0.04)$, conduct problems 1.48 vs. $1.64(\mathrm{P}=0.001)$, prosocial problems $1.81 \mathrm{vs}$. $1.87(\mathrm{P}=$ $0.01)$, emotional problems 1.43 vs. $1.50(\mathrm{P}=0.01)$, body attitude problems 2.21 vs. $2.15(\mathrm{P}=0.002)$, problems related to school environment 2.53 vs. $2.34(\mathrm{P}<0.001)$, and smoking and substance use 1.88 vs. $1.73(\mathrm{P}=0.001)$.

As indicated in Table 4, the incidence of cybervictimization was $20.7 \%(\mathrm{P}=0.04)$ in cases with physical problems, 25.8\% ( $\mathrm{P}=0.009)$ in cases with smoking and substance use, and $26.7 \%(P=0.02)$ in cases with a history of suicide. The term "physical problems" consisted of headaches, abdominal pain, and sleep disorders. The incidence of cyberbullying was $27.7 \%(\mathrm{P}=0.01)$ in cases with special diseases and $35.5 \%(\mathrm{P}<0.001)$ in cases with smoking and substance use. In a multivariate analysis using backward linear regression for cybervictimization (dependent variable), only the family situation (my parents with whom I live) and high school type were used in the model. Their coefficients were-0.098 and -0.103 , respectively. The formula applied was cybervictimization $=(0.412)+(-0.103 \times$ high school type grade 9$)$ $+(-0.098 \times$ family situation biology). In the multivariate analysis using backward linear regression for cyberbullying (dependent variable), only school type, sex, and father's job were considered in the model. Their coefficients were -0.080 and 0.051 , respectively. The implemented formula was cyberbullying $=(0.324)+(-0.80 \times$ high school type $)+$ $(0.088 \times$ sex01 $)+($ father's job01 $\times 0.051)$. 
Table 1. Association of Strengths and Difficulties Questionnaire and Other Variables with Cyberbullying and Cybervictimization Presented as Mean \pm SD and Their Corresponding P-values

\begin{tabular}{|c|c|c|c|c|c|c|}
\hline \multirow{2}{*}{$\begin{array}{l}\text { Computed } \\
\text { Variables }\end{array}$} & \multicolumn{2}{|c|}{ Cybervictimization, Mean (SD) } & \multirow[b]{2}{*}{ P-Value } & \multicolumn{2}{|c|}{ Cyberbullying, Mean (SD) } & \multirow{2}{*}{ P-Value } \\
\hline & No & Yes & & No & Yes & \\
\hline Height & $165.23(9.47)$ & $167.33(7.47)$ & $<0.001$ & $165.24(9.51)$ & $168.11(9.72)$ & $<0.001$ \\
\hline Weight & $58.12(13.99)$ & $61.95(15.42)$ & 0.001 & $58.36(14.45)$ & $60.31(13.89)$ & 0.58 \\
\hline BMI & $21.24(4.3)$ & $21.69(4.32)$ & 0.17 & $21.28(4.34)$ & $21.42(4.32)$ & 0.65 \\
\hline Peer problems & $1.76(0.3)$ & $1.81(0.33)$ & 0.03 & $1.76(0.30)$ & $1.80(0.32)$ & $<0.04$ \\
\hline Conduct problems & $1.49(0.34)$ & $1.65(0.39)$ & $<0.001$ & $1.48(0.34)$ & $1.64(0.37)$ & 0.001 \\
\hline $\begin{array}{l}\text { Hyperactivity } \\
\text { problems }\end{array}$ & $1.88(0.27)$ & $1.91(0.27)$ & 0.14 & $1.88(0.27)$ & $1.90(0.27)$ & $<0.34$ \\
\hline Prosocial problems & $1.82(0.33)$ & $1.85(0.32)$ & 0.16 & $1.81(0.33)$ & $1.87(0.33)$ & 0.01 \\
\hline $\begin{array}{l}\text { Emotional } \\
\text { problems }\end{array}$ & $1.42(0.43)$ & $1.57(0.45)$ & $<0.001$ & $1.43(0.44)$ & $1.50(0.44)$ & 0.01 \\
\hline $\begin{array}{l}\text { Thoughts about } \\
\text { body problems }\end{array}$ & $2.21(0.28)$ & $2.14(0.31)$ & 0.001 & $2.21(0.28)$ & $2.15(0.30)$ & 0.002 \\
\hline $\begin{array}{l}\text { School } \\
\text { environment } \\
\text { problems }\end{array}$ & $2.52(0.59)$ & $2.34(0.54)$ & $<0.001$ & $2.53(0.60)$ & $2.34(0.53)$ & $<0.001$ \\
\hline $\begin{array}{l}\text { Smoking and } \\
\text { substance use }\end{array}$ & $1.86(0.33)$ & $1.76(0.42)$ & 0.02 & $1.88(0.32)$ & $1.73(0.44)$ & 0.001 \\
\hline
\end{tabular}

\section{Discussion}

The primary goal of the study was to identify the prevalence of cyberbullying and cybervictimization in grades 7, 8, and 9 students. According to our findings, the rate of cyberbullying was calculated to be $22.3 \%$, while that of cybervictimization was $18 \%$. Since there are considerable discrepancies in cyberbullying definition, methodology, and culture, prevalence disparities of cyberbullying status have been observed in studies performed in different geographical locations worldwide. Nonetheless, there were similarities in the reported prevalence between our findings and most previous research, such as a systematic review study conducted in Spain (2015) that showed one out of every five people was involved in some form of cyberbullying (3), which is almost consistent with our findings. However, some previous research reported a prevalence of up to $72 \%$ (21), but some others reported a very low prevalence (22). In the latest survey among high school students in Iran, $34.2 \%$ cybervictimization, and $27.3 \%$ cyberbullying were reported, which showed a slightly higher prevalence than in our study (13). This great difference can be due to time, place, or method of investigation.

Another important objective was to determine the gender role in cyberbullying. Our study illustrated that boys were more likely to be bullied and victimized than girls, and this occurred more in older age groups $(\mathrm{P}<0.05)$. Similar to the present results, the majority of the previous studies confirm our findings of gender differences, such as a recent meta-analysis in China that reported boys were more involved than girls in cyberbullying perpetration behaviors (23). However, a recent study conducted by Razjouyan et al. in Iran showed that females were more likely to be victims than males, while males were bullied more than females $(\mathrm{P}<0.05)$ (13). Surprisingly, in a few studies such as cyberbullying surveys in Spain (2016) conducted in several different regions, no gender differences were found in cyberbullying perpetration (24).

Another finding of this study indicated significant correlations of Peer problems, conduct problems, and emotional problems (subscales of SDQ) with cybervictimization, and significant correlations of peer problems, conduct problems, prosocial problems, and emotional problems with cyberbullying (Table 4). Other subscales, such as thoughts about their body and school environment problems, had significant positive relationships with cybervictimization and cyberbullying. All of the subscales mentioned can be antecedents or consequences of cyberbullying and cybervictimization, and they harm the mental health.

Many surveys have evaluated the relationship between mental health problems, cyberbullying, and cybervictimization, as hinted by researchers such as Chadwick, who noted that hyperactivity, conduct problems, prosocial problems, perceived difficulties, psychosomatic symptoms (i.e., stomachache, headache, etc.), and feeling unsafe at school were experienced by the students involved 


\begin{tabular}{|c|c|c|c|c|c|}
\hline Demographic Variables & Frequency & Demographic Variables (\%) & Demographic Variables & Frequency & Demographic Variables (\%) \\
\hline Gender & & & Mother's occupation & & \\
\hline Male & 794 & 54.5 & Doctor & 17 & 1.3 \\
\hline Female & 662 & 45.5 & Engineer/teacher & 5 & 0.4 \\
\hline Age Groups & & & Teacher & 55 & 4.2 \\
\hline $12-13$ & 261 & 17.9 & Self-employed & 74 & 5.6 \\
\hline $14-15$ & 947 & 65 & Employee & 119 & 9.1 \\
\hline $16-17$ & 248 & 17 & Housewife & 1001 & 76.4 \\
\hline Grade & & & Unemployed & 7 & 0.5 \\
\hline 7th grade & 367 & 25.2 & Retired & 33 & 2.5 \\
\hline 8 th grade & 380 & 26.1 & Student background & & \\
\hline 9 th grade & 709 & 48.7 & Tehran origin & 946 & 65 \\
\hline High school type & & & Other & 510 & 35 \\
\hline Public & 1293 & 88.8 & Place of birth & & \\
\hline Private & 163 & 11.2 & Tehran & 1261 & 86.6 \\
\hline Parents with whom I live & & & Other & 195 & 13.4 \\
\hline Biological parents & 1330 & 93.1 & Native language & & \\
\hline $\begin{array}{l}\text { Biological father and foster } \\
\text { mother }\end{array}$ & 10 & 0.7 & Persian & 1409 & 96.8 \\
\hline $\begin{array}{l}\text { Biological mother and } \\
\text { foster father }\end{array}$ & 7 & 0.5 & Other languages & 47 & 3.2 \\
\hline Biological father alone & 14 & 1 & Birthplace of mother & & \\
\hline Biological mother alone & 55 & 3.9 & Tehran & 834 & 57.3 \\
\hline Adoptive child & 5 & 0.4 & Other & 621 & 42.7 \\
\hline Father's occupation & & & Native language of mother & & \\
\hline Doctor & 13 & 1 & Persian & 1293 & 88.8 \\
\hline Engineer/teacher & 71 & 5.4 & Other & 163 & 11.2 \\
\hline Teacher & 20 & 1.5 & Birthplace of father & & \\
\hline Self-employed & 594 & 45 & Tehran & 780 & 53.6 \\
\hline Employee & 447 & 33.9 & Other & 675 & 46.4 \\
\hline Laborer & 45 & 3.4 & Native language of father & & \\
\hline Unemployed & 15 & 1.1 & Persian & 1266 & 87 \\
\hline Retired & 62 & 4.7 & Other languages & 190 & 13 \\
\hline Others & 53 & 4 & & & \\
\hline
\end{tabular}

(11). Other analogous studies such as Samara's research found that cyber victims had emotional and peer problems, low self-esteem, and high levels of depressive symptoms, whilst cyberbullies demonstrated conduct problems, hyperactivity, and prosocial problems. Victims reported high rates of self-injury and suicidal tendencies and experienced long-term health risks. Also, being a bully is a risk factor for depression, anxiety, eating disorders, smoking, and substance abuse (25). Hamm's obser- vations showed links between emotional problems, Peer problems and conduct problems, hyperactivity problems, and prosocial problems and cyberbully status, as well as between conduct, hyperactivity, emotional, and peer problems and cyber-victim status. Our findings support, to some extent, the results of studies conducted by a major author in this topic in which Sourander's survey indicated that Cybervictim-only status was associated with perceived difficulties, emotional and peer problems, and 


\begin{tabular}{|c|c|c|c|c|c|c|}
\hline \multirow{2}{*}{$\begin{array}{l}\text { Demographic } \\
\text { Variables }\end{array}$} & \multicolumn{2}{|c|}{ Cybervictimization, No. (\%) } & \multirow{2}{*}{ P-Value } & \multicolumn{2}{|c|}{ Cyberbullying, No. (\%) } & \multirow{2}{*}{ P-Value } \\
\hline & No & Yes & & No & Yes & \\
\hline Age Groups & & & 0.002 & & & 0.002 \\
\hline $12-13$ & $230(89.5)$ & $27(10.5)$ & & $220(85.9)$ & $36(14.1)$ & \\
\hline $14-15$ & $752(80.9)$ & $177(19.1)$ & & $701(75.9)$ & $223(24.1)$ & \\
\hline $16-17$ & $193(78.1)$ & $54(21.9)$ & & $187(76.0)$ & $59(24.0)$ & \\
\hline Gender & & & 0.05 & & & $<0.001$ \\
\hline Male & $638(80.5)$ & $155(19.5)$ & & $581(73.6)$ & $208(26.4)$ & \\
\hline Female & $537(83.09)$ & $103(16.1)$ & & $527(82.7)$ & $110(17.3)$ & \\
\hline Grade & & & $<0.001$ & & & $<0.001$ \\
\hline 7 th grade & $323(89.2)$ & $39(10.8)$ & & $313(86.7)$ & $48(13.3)$ & \\
\hline 8 th grade & $297(80.9)$ & $70(19.1)$ & & $268(73.6)$ & $96(26.4)$ & \\
\hline 9th grade & $555(78.8)$ & $149(21.2)$ & & $527(75.2)$ & $174(24.8)$ & \\
\hline High school type & & & 0.06 & & & 0.008 \\
\hline Public & $1049(82.6)$ & $221(17.4)$ & & $995(78.7)$ & $269(21.3)$ & \\
\hline Private & $126(77.3)$ & $37(22.7)$ & & $113(69.8)$ & $49(30.2)$ & \\
\hline $\begin{array}{l}\text { Parents with whom I } \\
\text { live }\end{array}$ & & & 0.2 & & & 0.07 \\
\hline $\begin{array}{l}\text { Biological } \\
\text { parents }\end{array}$ & $1076(82.3)$ & $232(17.7)$ & & $1018(78.2)$ & $284(21.8)$ & \\
\hline $\begin{array}{l}\text { Only father or } \\
\text { mother }\end{array}$ & $71(78.9)$ & $19(21.1)$ & & $63(70.8)$ & $26(29.2)$ & \\
\hline Father's occupation & & & 0.43 & & & 0.15 \\
\hline Doctor & $12(92.3)$ & $1(7.7)$ & & $12(92.3)$ & $1(7.70)$ & \\
\hline Engineer & $60(87)$ & $9(13)$ & & $51(73.9)$ & $18(26.1)$ & \\
\hline Teacher & $17(89.5)$ & $2(10.5)$ & & $16(88.9)$ & $2(11.1)$ & \\
\hline Self-Employed & $474(80.9)$ & $112(19.1)$ & & $433(74.3)$ & $150(25.7)$ & \\
\hline Employee & $355(80.1)$ & $88(19.9)$ & & $351(79.4)$ & $91(20.6)$ & \\
\hline Laborer & $38(88.4)$ & $5(11.6)$ & & $35(81.4)$ & $8(18.6)$ & \\
\hline Unemployed & $14(93.3)$ & $1(6.7)$ & & $11(73.3)$ & $4(26.7)$ & \\
\hline Retired & $53(86.9)$ & $8(13.1)$ & & $53(86.9)$ & $8(13.1)$ & \\
\hline Others & $43(84.3)$ & $8(15.7)$ & & $38(73.1)$ & $14(26.9)$ & \\
\hline Mather's occupation & & & 0.37 & & & 0.46 \\
\hline $\begin{array}{l}\text { Doctor or } \\
\text { engineer }\end{array}$ & $21(95.5)$ & $1(4.5)$ & & $17(77.3)$ & $5(22.7)$ & \\
\hline Teacher & $48(80.9)$ & $6(11.1)$ & & $46(85.2)$ & $8(14.8)$ & \\
\hline Self-employed & $59(80.8)$ & $14(19.2)$ & & $54(75.0)$ & $15(25.0)$ & \\
\hline Employee & $97(82.9)$ & $20(17.1)$ & & $99(83.9)$ & $19(16.1)$ & \\
\hline Housewife & $798(80.9)$ & $188(19.1)$ & & $746(76.0)$ & $236(24)$ & \\
\hline Retired & $5(71.4)$ & $2(28.6)$ & & $5(71.4)$ & $2(28.60)$ & \\
\hline Others & $28(87.5)$ & $4(12.5)$ & & $28(90.3)$ & $3(9.7)$ & \\
\hline
\end{tabular}

not feeling safe at school. Cyberbully-only status was associated with perceived difficulties, hyperactivity, conduct problems, and not feeling safe at school. Cyberbully-victim status was associated with all of these risk factors (5). 


\begin{tabular}{|c|c|c|c|c|c|c|}
\hline \multirow{2}{*}{ Variables } & \multicolumn{2}{|c|}{ Cyber victim, No. (\%) } & \multirow{2}{*}{ P-value } & \multicolumn{2}{|c|}{ Cyberbully, No. (\%) } & \multirow{2}{*}{ P-value } \\
\hline & No & Yes & & No, No. (\%) & Yes, & \\
\hline Special disease & & & 0.13 & & & 0.01 \\
\hline No & $975(82.6)$ & $206(17.4)$ & & $928(78.8)$ & $249(21.2)$ & \\
\hline Physical problems & & & 0.04 & & & 0.18 \\
\hline No & $423(83.3)$ & $85(16.7)$ & & $396(78.1)$ & $111(21.9)$ & \\
\hline Yes & $625(79.3)$ & $163(20.7)$ & & $594(75.8)$ & $190(24.2)$ & \\
\hline Smoking and substance use & & & 0.009 & & & $<0.001$ \\
\hline No & $457(85.1)$ & $80(14.9)$ & & $444(83.1)$ & $90(16.9)$ & \\
\hline Suicide & & & 0.02 & & & 0.15 \\
\hline No & $482(86.4)$ & $88(15.4)$ & & $460(81)$ & $108(19)$ & \\
\hline Yes & $44(73.3)$ & $16(26.7)$ & & $44(74.6)$ & $15(25.4)$ & \\
\hline
\end{tabular}

Another interesting finding of our study was the association of smoking and substance use with both cyberbullies and victims. The findings were consistent with those of Sherill et al. (2016) and Sourander et al (2010) studies that found that greater cybervictimization was associated with a greater frequency of smoking and drinking (5). Similarly, Mishna et al. (2016) showed that the youth who committed cyberbullying had an increased risk of smoking and substance use. A significant relationship was found in our study between suicide and cybervictimization that is consistent with that of the Hinduja study, which reported that cyber victims and cyberbullies were 1.9 and 1.5 times more likely to commit suicide than others (26). As mentioned in the results, age group and high school grade had significant associations with cyberbullying and cybervictimization but not high school type.

The current study and comparative surveys examined the correlation of variables with traditional bullying and cyberbullying, but what needs to be done in future investigations is to evaluate how to enhance community standards and more importantly, individual skills and selfesteem to reduce violent behaviors and their negative effects. This is the first cross-sectional study on cyberbullying among junior high school students in Tehran, in which cyberbullying behavior was evaluated based on a questionnaire with the Strengths and Difficulties Questionnaire (SDQ) subsection as the main component. Also, no research has been conducted in Iran with a comprehensive survey of related factors.

However, these findings are limited by the use of a cross-sectional design. Therefore, the results cannot be used to obtain any causal interaction. Hence, a longitudi- nal study is recommended for this purpose. Besides, the results may not be generalizable to students in other areas of the country, as we could not directly compare cyberbullying and cybervictimization among students in different cities. Additionally, we only included junior high school students (grades 7-9), which is not holistic. Since cyberbullying is common at all ages, we suggest that other school grades be considered in future studies on cyberbullying. Another limitation of this study was a relatively low sample size. Accordingly, our findings should be used with caution.

\subsection{Conclusions}

Overall, our study revealed that cyberbullying behaviors are prevalent among adolescents and that gender plays a crucial role in cyberbullying behaviors. Emotional, prosocial, conduct, and peer problems, as well as demographic, physical, and behavioral characteristics, have a significant correlation with cyberbullying and cybervictimization. Smoking and substance use and suicide attempts occur commonly in this population. Our evidence can be used by decision-makers and policymakers to plan preventive strategies for future interventions including socialization skills training, problem-solving, and skills in forming friendships. Finally, this information can be provided to teachers, staff, and families to guide them on measures to assist children.

\section{Supplementary Material}

Supplementary material(s) is available here [To read supplementary materials, please refer to the journal web- 
site and open PDF/HTML].

\section{Footnotes}

Authors' Contribution: Study concept and design: Z. Z. and SH. A.; Acquisition of data: M. M.; Analysis and interpretation of data: F. T. and Z.Z.; Drafting of the manuscript: M. S.; Critical revision of the manuscript for important intellectual content: F. T., A. N., and M. M.; Study supervision: Z. Z

Conflict of Interests: The authors declare that they have no conflict of interest.

\section{Ethical Approval: IR.TUMS.MEDICINE.REC.1394.1413.}

Funding/Support: There is no financial support to disclose. The authors have funded the paper.

Informed Consent: The participants' informed consent was received.

\section{References}

1. Li Q, Cross D, Smith PK. Cyberbullying in the global playground: Research from international perspectives. Oxford: Wiley-Blackwell; 2012. doi: 10.1002/9781119954484.

2. Machimbarrena JM, Garaigordobil M. Bullying/Cyberbullying in 5th and 6th grade: differences between public and private schools. Anales de Psicología. 2017;33(2):319. doi: 10.6018/analesps.33.2.249381.

3. Zych I, Ortega-Ruiz R, Del Rey R. Systematic review of theoretical studies on bullying and cyberbullying: Facts, knowledge, prevention, and intervention. Aggress Violent Behav. 2015;23:1-21. doi: 10.1016/j.avb.2015.10.001.

4. Barlett C, Coyne SM. A meta-analysis of sex differences in cyberbullying behavior: the moderating role of age. Aggress Behav. 2014;40(5):474-88. doi: 10.1002/ab.21555. [PubMed: 25098968].

5. Sourander A, Brunstein Klomek A, Ikonen M, Lindroos J, Luntamo $\mathrm{T}$, Koskelainen M, et al. Psychosocial risk factors associated with cyberbullying among adolescents: a population-based study. Arch Gen Psychiatry. 2010;67(7):720-8. doi: 10.1001/archgenpsychiatry.2010.79. [PubMed: 20603453].

6. Mishna F, McInroy LB, Lacombe-Duncan A, Bhole P, Van Wert M, Schwan K, et al. Prevalence, motivations, and social, mental health and health consequences of cyberbullying among school-aged children and youth: Protocol of a longitudinal and multi-perspective mixed method study. JMIR Res Protoc. 2016;5(2). e83. doi: 10.2196/resprot.5292. [PubMed: 27220556]. [PubMed Central: PMC4897298].

7. Jenaro C, Flores N, Vega V, Cruz M, Perez MC, Torres VA. Cyberbullying among adults with intellectual disabilities: Some preliminary data. Res Dev Disabil. 2018;72:265-74. doi: 10.1016/j.ridd.2017.12.006. [PubMed: 29227959].

8. Chan SF, La Greca AM. Cyber victimization and aggression: Are they linked with adolescent smoking and drinking? Child Youth Care Forum. 2015;45(1):47-63. doi: 10.1007/s10566-015-9318-x.

9. Parks PJ. Cyberbullying. San Diego: ReferencePoint Press; 2013.

10. Nikolaou D. Does cyberbullying impact youth suicidal behaviors? $J$ Health Econ. 2017;56:30-46. doi: 10.1016/j.jhealeco.2017.09.009. [PubMed: 28968528].
11. Chadwick S. Impacts of cyberbullying, building social and emotional resilience in schools (springerbriefs in education). 2014th ed. London: Springer; 2014.

12. Mohseny M, Zamani Z, Akhondzadeh Basti S, Sohrabi MR, Najafi A, Zebardast J, et al. Bullying and victimization among students bears relationship with gender and emotional and behavioral problems. Iran J Psychiatry. 2019;14(3):211-20. [PubMed: 31598124]. [PubMed Central: PMC6778606].

13. Razjouyan K, Hirbod Mobarake A, Sadr SS, Samimi Ardestani SM Yaseri $M$. The relationship between emotional intelligence and the different roles in cyberbullying among high school students in Tehran. Iran J Psychiatry Behav Sci. 2018;In Press(In Press). doi 10.5812 /ijpbs.11560.

14. Rønning JA, Handegaard BH, Sourander A, Mørch W. The Strengths and Difficulties Self-Report Questionnaire as a screening instrument in Norwegian community samples. Eur Child Adolesc Psychiatry. 2004;13(2):73-82. doi: 10.1007/s00787-004-0356-4.

15. Shahrivar Z, Tehrani-Doost M, Pakbaz B, Rezaie A, Ahmadi F. Normative data and psychometric properties of the parent and teacher versions of the strengths and difficulties questionnaire (SDQ) in an Iranian community sample. J Res Med Sci. 2009;14(2):69-77. [PubMed: 21772865]. [PubMed Central: PMC3129092].

16. Solberg ME, Olweus D. Prevalence estimation of school bullying with the Olweus Bully/Victim Questionnaire. Aggress Behav. 2003;29(3):239-68. doi: 10.1002/ab.10047.

17. Goodman A, Goodman R. Strengths and difficulties questionnaire as a dimensional measure of child mental health. J Am Acad Child Adolesc Psychiatry. 2009;48(4):400-3. doi: 10.1097/CHI.0b013e3181985068. [PubMed: 19242383].

18. Koskelainen M, Sourander A, Vauras M. Self-reported strengths and difficulties in a community sample of Finnish adolescents. Eur Child Adolesc Psychiatry. 2001;10(3):180-5. doi: 10.1007/s007870170024 [PubMed: 11596818].

19. Goodman R. The extended version of the Strengths and Difficulties Questionnaire as a guide to child psychiatric caseness and consequent burden. J Child Psychol Psychiatry. 1999;40(5):791-9. [PubMed: 10433412].

20. Goodman R. The Strengths and Difficulties Questionnaire: a research note. J Child Psychol Psychiatry. 1997;38(5):581-6. doi: 10.1111/j.14697610.1997.tb01545.x. [PubMed: 9255702].

21. Juvonen J, Gross EF. Extending the school grounds? Bullying experiences in cyberspace. $J$ Sch Health. 2008;78(9):496-505. doi: 10.1111/j.1746-1561.2008.00335.x. [PubMed: 18786042].

22. Hemphill SA, Heerde JA. Adolescent predictors of young adult cyberbullying perpetration and victimization among Australian youth. $J$ Adolesc Health.2014;55(4):580-7. doi:10.1016/j.jadohealth.2014.04.014. [PubMed: 24939014]. [PubMed Central: PMC4295930].

23. Sun S, Fan X, Du J. Cyberbullying perpetration: A meta-analysis of gender differences. Int J Internet Sci. 2016;11(1).

24. Romera EM, Cano J, García-Fernández CM, Ortega-Ruiz R. Cyberbullying: Social competence, motivation and peer relationships. Comunicar. 2016;24(48):71-9. doi: 10.3916/c48-2016-07.

25. Samara M, Burbidge V, El Asam A, Foody M, Smith PK, Morsi H Bullying and cyberbullying: Their legal status and use in psychological assessment. Int I Environ Res Public Health. 2017;14(12). doi: 10.3390/ijerph14121449. [PubMed: 29186780]. [PubMed Central: PMC5750868].

26. Hinduja S, Patchin JW. Bullying, cyberbullying, and suicide. Arch Suicide Res. 2010;14(3):206-21. doi:10.1080/13811118.2010.494133. [PubMed: 20658375] 